TITLE:

\title{
Single-Molecule Manipulation of the Duplex Formation and Dissociation at the G-Quadruplex/i- Motif Site in the DNA Nanostructure
}

\author{
$\operatorname{AUTHOR}(\mathrm{S})$ : \\ M, Endo; X, Xing; X, Zhou; T, Emura; K, Hidaka; B, \\ Tuesuwan; $H$, Sugiyama
}

\section{CITATION:}

M, Endo ...[et al]. Single-Molecule Manipulation of the Duplex Formation and Dissociation at the G-Quadruplex/i-Motif Site in the DNA Nanostructure. ACS nano 2015, 9(10): 99229929

ISSUE DATE:

2015-10-27

URL:

http://hdl.handle.net/2433/230920

\section{RIGHT:}

This document is the Accepted Manuscript version of a Published Work that appeared in final form in ACS nano, copyright (c) American Chemical Society after peer review and technical editing by the publisher. To access the final edited and published work see https://doi.org/10.1021/acsnano.5b03413. The full-text file will be made open to the public on 27 October 2016 in accordance with publisher's 'Terms and Conditions for Self-Archiving'. This is not the published version. Please cite only the published version.この論文は出版社版でありません。引用の際には出版社版を ご確認ご利用ください。 


\title{
Single-Molecule Manipulation of the Duplex
}

\section{Formation and Dissociation at the G-quadruplex/i-}

\section{motif Site in the DNA Nanostructure}

\author{
Masayuki Endo, ${ }^{*+}$ Xiwen Xing,,$^{\ddagger}$ Xiang Zhou, ${ }^{\circledR}$ Tomoko Emura, ${ }^{\ddagger}$ Kumi Hidaka, ${ }^{\ddagger}$ Bodin \\ Tuesuwan, Hiroshi Sugiyama*t»s
}

†Institute for Integrated Cell-Material Sciences (WPI-iCeMS), Kyoto University, Yoshidaushinomiyacho, Sakyo-ku, Kyoto 606-8501, Japan

$\ddagger$ Department of Chemistry, Graduate School of Science, Kyoto University, Kitashirakawaoiwakecho, Sakyo-ku, Kyoto 606-8502, Japan

CREST, Japan Science and Technology Corporation (JST), Sanbancho, Chiyoda-ku, Tokyo 102-

$$
\text { 0075, Japan }
$$

College of Chemistry and Molecular Sciences, Key Laboratory of Biomedical Polymers of Ministry of Education, Wuhan University, Wuhan, Hubei 430072, P. R. China

Department of Food and Pharmaceutical Chemistry, Faculty of Pharmaceutical Sciences, Chulalongkorn University, Bangkok 10330, Thailand

ABSTRACT 
We demonstrate the single-molecule operation and observation of the formation and resolution of double-stranded DNA (dsDNA) containing a G-quadruplex (GQ) forming and counterpart imotif forming sequence in the DNA nanostructure. Sequential manipulation of DNA strands in the DNA frame was performed to prepare a topologically controlled GQ/i-motif dsDNA. Using the strand displacement and the addition and removal of $\mathrm{K}^{+}$, the topologically controlled $\mathrm{GQ} / \mathrm{i}^{-}$ motif dsDNA in the DNA frame was obtained in high yield. The dsDNA was resolved into the single-stranded DNA, GQ, and i-motif by the addition of $\mathrm{K}^{+}$and operation in the acidic condition. The dissociation of the dsDNA under the GQ and i-motif formation condition was monitored by high-speed atomic force microscopy (AFM). The results indicate that the dsDNA containing the GQ- and i-motif sequence is effectively dissolved when the duplex is helically loosened in the DNA nanoscaffold. 
Tandem G-rich repeat sequences, which form G-quadruplex (GQ) structures, are often observed in the promoter regions. ' The GQ is thought to be closely involved in biological functions such as the regulation of gene expression and cell fate control. ${ }^{2}$ Promoter sequences such as the $c-m y c$ promoter contain the G-rich sequence, which forms a GQ structure that is involved in the regulation of transcription. = In the double-stranded DNA (dsDNA) in this region, the complementary sequence contains a C-rich repeat sequence, which forms i-motif structure. ${ }^{3} \mathrm{~A}$ number of studies have reported on the formation of the GQ and/or i-motif in the promoter regions containing GQ- and i-motif-forming sequences. ${ }^{4567}$

The i-motif structure is physically induced in an acidic condition because the i-motif formation requires a hemiprotonated cytosine dimer formation. ${ }^{3}$ However, when using some C-rich sequences, such as the proximal promoter region of RET oncogene, the i-motif structure can be formed close to the neutral $\mathrm{pH}$ condition. ${ }^{8}$ In addition, i-motif formation at neutral $\mathrm{pH}$ has also been observed in a dsDNA with negative superhelicity's and in a molecular crowding environment. ${ }^{9}$ A promoter sequence such as the insulin-linked polymorphic region (ILPR) containing 5'-ACA(GGGGTGT) $)_{4}-3^{\prime}$ has been investigated, and the unfolding and folding of the GQ and i-motif in the ILPR sequence has been investigated at the single-molecule level using optical tweezers by measuring the unfolding force by mechanical unfolding of the structures under the different $\mathrm{pH}$ and ionic conditions. ${ }^{6} 7^{10}$

These unique structures have been recently used as sensors for the detection of DNA molecules and molecular switching devices that are responsive to ions and $\mathrm{pH}$. ${ }_{12}^{12}{ }_{13}$ The manipulation of these structures is also an interesting target for the construction of structurebased sensors in nanotechnology. ${ }^{11213}$

Using DNA nanostructures and high-speed atomic force microscopy (AFM) imaging techniques, direct observation of the DNA structural changes at the single-molecule level has been recently reported. ${ }^{14}$ In these experiments, the individual target DNA structures to be observed were assembled in a frame-like DNA nanostructure, called a DNA frame, and the movement of the DNA strands containing unique sequences in the DNA frame was investigated. 
For example, single-molecule G-multiplex structures and their reconfiguration were visualized in the DNA frame, ${ }^{15}$ and the B-Z transitions, ${ }^{16}$ and the imaging of association and dissociation of photoresponsive DNA strands ${ }^{17}$ were demonstrated. The enzyme behaviors and reactions in the DNA frame structures were also investigated using the designed nanostructures and high-speed AFM. ${ }^{18}$

In this study, we manipulated the formation and dissociation of the $\mathrm{GQ} / \mathrm{i}$-motif complementary sequence in the ILPR core sequence in the DNA frame structure (Figure 1). The ILPR promoter region is considered to separate into the GQ and i-motif structures in the regulation of transcription. 'The GQ/i-motif sequence was introduced into the DNA frame for observation of the GQ and i-motif formation under the various conditions. In this system, topologically controlled dsDNA was prepared using the sequential manipulation of the interaction of DNA strands in a series of programmed operations. We performed the resolution of dsDNA containing the $\mathrm{GQ} / \mathrm{i}$-motif sequence by controlling the $\mathrm{pH}$ and $\mathrm{K}^{+}$conditions which were changed individually or together during the formation of the GQ and i-motif. Furthermore, these structural changes were directly observed by high-speed AFM at the single-molecule level.

\section{Results and Discussion}

\section{GQ and i-motif formation in the DNA frame.}

We examined the GQ and i-motif formation in a $\mathrm{pH} 7.6$ or $\mathrm{pH} 5.5$ solution containing $50 \mathrm{mM}$ $\mathrm{KCl}$. CD spectra measurements were employed to investigate the formation of the GQ- and imotif-structures using individual GQ- and i-motif-forming sequences. ${ }^{19}$ In the case of the GQ formation, the $\mathrm{CD}$ band specific for the GQ increased in the presence of $50 \mathrm{mM} \mathrm{KCl}$, indicating that the GQ structures formed at both $\mathrm{pH} 7.6$ and 5.5 (Figure 2a). The CD bands show the characteristics of a mixture of parallel $\left(\lambda_{\max }=265 \mathrm{~nm} ; \lambda_{\min }=238 \mathrm{~nm}\right)$ and antiparallel $\left(\lambda_{\max }=293\right.$ $\mathrm{nm}$ ) GQ structures (Figure 1c). ${ }^{19}$ In the case of the i-motif formation, the CD band specific for imotif $\left(\lambda_{\max }=290 \mathrm{~nm} ; \lambda_{\min }=263 \mathrm{~nm}\right)$ appeared at $\mathrm{pH} 5.5$ both in the absence and presence of $\mathrm{KCl}$, indicating that the $\mathrm{i}$-motif formed in the acidic condition (Figure 2d). ${ }^{6,8} \mathrm{Next}$, we examined the 
GQ and i-motif formation in the DNA nanostructure. We divided the GQ-forming sequence into two fragments and introduced them in the middle of the two supporting dsDNAs in the DNA frame (Figure 2b and Figure S1). ${ }^{\text {ssa }}$ When the GQ formed in the center, two separated supporting dsDNAs should be connected and would be observed as an X-shape in the DNA frame (Figure 2b). Before the addition of $\mathrm{KCl}$, two dsDNAs were clearly separated in the AFM images. After the addition of $\mathrm{KCl}$, the $\mathrm{X}$-shaped dsDNAs appeared, indicating the formation of the GQ structure in the DNA frame. The yield of the X-shape formation in the presence of $\mathrm{K}^{+}$was $68 \%$, while in the initial state, the separated structure formed in 93\% yield (Figure 2c). In addition, using the acidic condition at $\mathrm{pH} 5.5$ with $\mathrm{K}^{+}$, the GQ formation was still observed in $58 \%$ yield. The formation of the GQ was clearly induced by the addition of $\mathrm{K}^{+}$in the DNA frame.

We also examined the i-motif formation in the DNA frame. Using the divided i-motif-forming sequence, these two short strands were introduced between the two supporting dsDNAs (Figure 2e and Figure S1). When the i-motif formed in the center, two separated strands should be connected and observed as an X-shape in the DNA frame (Figure 2e). At pH 7.6, two dsDNAs were clearly separated and had a yield of $99 \%$ in the AFM images. After changing to the $\mathrm{pH} 5.5$ condition, $\mathrm{X}$-shaped dsDNAs appeared in $56 \%$ and $69 \%$ in the presence and absence of $\mathrm{K}^{+}$, respectively. These results indicate that the formation of the GQ and i-motif can be controlled in the DNA frame by altering the $\mathrm{K}^{+}$and acidic condition. We further used the conditions obtained in the bimolecular GQ and i-motif formation for the intrastrand GQ and i-motif formation from the GQ/i-motif duplex in the DNA frame.

\section{Operation to prepare a topologically controlled dsDNA in the DNA frame.}

We next constructed a topologically controlled dsDNA in the DNA frame. To observe the resolution of the dsDNA containing GQ/i-motif sequence in the DNA frame, two strands should be introduced into the DNA frame separately. If the two strands are incorporated into the DNA frame at the same time, the complementary GQ/i-motif parts hybridize to form a double helix. Therefore, if the hybridized GQ/i-motif duplex is introduced into the DNA frame, the locked 
state of the duplex which is not resolved into GQ and i-motif strands should be preserved (described later). As shown in Figure 3a, we introduced GQ-forming single-stranded DNA (ssDNA) and i-motif-forming ssDNA separately into the top and bottom sides of the DNA frame, respectively (Figure S3). Here we used the core sequence of GQ and i-motif forming sequence in the ILPR promoter. Using these sequences, we confirmed the usual GQ and i-motif formation in the CD spectra as reported previously (Figure 2a and 2d). ${ }^{6}{ }^{19}$ We introduced them sequentially using a stepwise operation. First, the DNA strand with the i-motif sequence was introduced into the bottom side of the DNA frame (State A). Here, the i-motif sequence was covered with toehold-containing complementary strand to prevent the binding to the GQ ssDNA in the next step. The i-motif sequence covered with a complementary strand having a toehold part was incorporated into the bottom side. Next, a GQ-forming DNA strand was incorporated into the top side in the DNA frame (State B). Here, the strand containing GQ structure in the presence of $\mathrm{K}^{+}$ was incorporated into the DNA frame to avoid the strand exchange between the protection strand of i-motif sequence and GQ-forming strand. In the AFM image, the two separated strands were observed in the DNA frame in $81 \%$ yield (Figure 3 b left and Figure S4a).

In the third step, the toehold-containing protection strand was removed from the bottom strand by strand displacement using a fully complementary strand (State C). After the strand displacement in the presence of $\mathrm{K}^{+}$, two strands remained unbound in $76 \%$ yield, as shown in the previous step (Figure $3 \mathrm{~b}$ center and Figure S4b). This indicates that the GQ structure prevented binding to the complementary i-motif-forming sequence.

Finally, $\mathrm{K}^{+}$was removed by ultrafiltration to induce the formation of $\mathrm{GQ} / \mathrm{i}$-motif dsDNA (State D). In the AFM image, most of the supporting dsDNAs in the DNA frame formed the X-shape (Figure $3 b$ right and Figure S4c), indicating that the GQ- and i-motif ssDNA hybridized to form a duplex. The yield of GQ/i-motif duplex formation was 89\% (Figure 3c). Using these operations, we successfully prepared the topologically controlled GQ/i-motif dsDNA in the DNA frame. The prepared GQ/i-motif duplex could be used for the resolution of the duplex into the GQ and/or imotif structure under the GQ- and i-motif-forming conditions. 
Hybridization of the GQ ssDNA and i-motif ssDNA into the GQ/i-motif duplex were observed by high-speed AFM (Figure 3d). Two separated strands in the DNA frame (State C to D) in the presence of $\mathrm{K}^{+}$were adsorbed onto mica, and AFM imaging was performed in the buffer without $\mathrm{K}^{+}$. During AFM scanning, two separated strands were connected to form an X-shaped structure. At $15 \mathrm{~s}$, two strands were partially attached, and at $20 \mathrm{~s}$, these were connected and hybridized, which was observed as a single line in the middle. The hybridized strand never reverted to two strands. These results suggest that the process for the X-shape formation was initiated by disruption of the GQ structure by removal of $\mathrm{K}^{+}$and the subsequent hybridization of the GQ- and i-motif-forming ssDNAs.

Manipulation of the topologically controlled dsDNA to resolve into the GQ and $i$-motif in the DNA frame.

To investigate the resolution of the ILPR promoter domain containing the GQ- and i-motifforming sequence, the prepared GQ/i-motif duplex was dissociated into two strands under the GQ- and i-motif-forming conditions (Figure 4a). We used the three conditions described in the first section (Figure 2): (i) GQ-forming condition ( $\mathrm{pH} \mathrm{7.6,} \mathrm{K+;} \mathrm{State} 1$ to 2); (ii) i-motif-forming condition ( $\mathrm{pH} 5.5$; DNA State 1 to 3); and (iii) GQ- and i-motif-forming condition ( $\mathrm{pH} 5.5, \mathrm{~K}^{*}$; State 1 to 4) (Figure 4a). In the first operation (i), the duplex in the initial state (State 1), which formed in $91 \%$ yield, was treated with $\mathrm{K}^{+}$-containing buffer at $\mathrm{pH} 7.6$. In this condition, the GQ formation should resolve the GQ/i-motif duplex. As observed in AFM images, $51 \%$ of the structures separated into two strands (Figure $4 \mathrm{~b}$ and Figure S5a). This result indicates that the formation of the GQ structure can induce the resolution of the manipulated GQ/i-motif duplex under the GQ-forming condition.

In the second operation (ii), the $\mathrm{pH} 5.5$ condition was used to induce the formation of the imotif structure. In this condition, the separated dsDNAs yielded in 38\% (Figure 4b and Figure $\mathrm{S} 5 \mathrm{~b})$. This result indicates that the formation of the i-motif structure can also solve the GQ/imotif duplex. 
In the third operation (iii), the GQ/i-motif duplex was exposed to the acidic condition in the presence of $\mathrm{K}^{+}$. The duplex also separated into two dsDNAs in the DNA frame (Figure 4b and Figure S5c). The yield of the separated strands increased to 58\%. In this condition, the GQ and imotif formation occurred at the same time, and the separated strands were observed clearly, because the formation of the GQ and i-motif structure should tighten the individual strands. These results indicate that the GQ and i-motif formation induces the resolution of the GQ/i-motif dsDNA formed in the DNA frame. The yield of resolution of GQ/i-motif duplex is still moderate (50-60\%) at rt, so that, to promote the dissociation of the duplex and formation of the GQ and imotif structure, the other factors such as temperature are needed to be examined further.

From these results, incubation with $\mathrm{K}^{+}$, which induces the formation of the GQ structure, always promotes the resolution of the GQ/i-motif duplex. On the other hand, the i-motif formation needs the acidic condition which unlikely occurs in the promoter region in the transcription. For the i-motif formation, $\mathrm{pH}$ should be kept to low because the protonation to the cytosine is required. In the $\mathrm{CD}$ spectra of i-motif forming strand, the i-motif formation and deformation occurred at slightly acidic condition ranging between pH 6.0 and 6.5 (Figure S6a). We also examine the $\mathrm{pH}$ induced separation of the $\mathrm{GQ} / \mathrm{i}$-motif duplex at $\mathrm{pH} 6.0$ and 6.5 . In the pH 6.0 buffer, the GQ/i-motif duplex was separated into two strands, indicating that the formation of the i-motif induced the duplex dissociation (Figure S6b). On the other hand using pH 6.5 condition, the GQ/i-motif duplex was not resolved (Figure S6c). These results suggest that the i-motif formation can resolve the GQ/i-motif duplex at slightly acidic condition, which should depend on the GQ/i-motif sequence in the promoter domain and environment such as crowding condition. ${ }^{9}$

The GQ/i-motif duplex prepared in the DNA frame is a topologically controlled duplex. Two topologically separated ssDNA rings containing the GQ and i-motif sequence hybridized to form the GQ/i-motif duplex in the DNA frame. Here, single-stranded linkers connecting GQ- (or imotif-) forming strands and supporting dsDNAs were added to be able to hybridize GQ-/i-motifforming strands (Figures 3a and S3). When the GQ/i-motif duplex is formed, the GQ/i-motif 
duplex should be pulled by the single-stranded linkers from four terminals, which should work as

a torque for unwinding the formed double helix. Therefore, this GQ/i-motif duplex should contain negative helicity to loosen the duplex. As reported previously, the GQ/i-motif doublehelical domain with negative helicity promotes the dissociation of the duplex in the formation of the GQ structure. ${ }^{5}$ In our system, resolution of the duplex can be easily induced in the $\mathrm{K}^{+}$and acidic condition. Therefore, using this topologically controlled duplex, the torque to loosen the double helix effectively worked to resolve the GQ/i-motif duplex coupled with the formation of the GQ and i-motif structure.

The advantage to use this topologically controlled GQ/i-motif duplex was proved by comparing with the usually formed duplex placed in the DNA frame. The GQ/i-motif duplex was introduced into the DNA frame just by annealing without using a stepwise operation as shown in Figure 3. The usually formed GQ/i-motif duplex was not resolved into two separated strands in the $\mathrm{K}^{+}$and acidic condition (Figure S7). As previously described once the usual duplex is fixed in the DNA frame, the duplex cannot resolve into the GQ and i-motif ssDNA. These results indicate that the topological control in the DNA frame suitably works to prepare a model of the $\mathrm{GQ} / \mathrm{i}$-motif duplex occurred in the promoter region.

High-speed AFM observation of the resolution of the GQ/i-motif duplex in the DNA frame.

We used high-speed AFM to further examine the separation of the GQ/i-motif duplex at the single-molecule level (Figure 4d-f). We prepared samples containing the GQ/i-motif duplex and kept them in $\mathrm{pH} 7.6$ buffer in the initial condition. The duplex samples were then observed by high-speed AFM under the three different conditions shown in Figure 4a. The prepared samples were adsorbed onto a mica plate and then observed in the observation buffer containing $\mathrm{K}^{+}$and pH 5.5 buffer.

First, we examined the separation in the GQ-forming condition with $\mathrm{K}^{+}$and $\mathrm{pH} 7.6$ buffer. The $\mathrm{X}$-shaped structure in the parallel conformation changed into separated two strands during AFM scanning (Figure 4d). The separation of the dsDNA and the corresponding conversion of the X- 
shaped structure into the separated strands occurred at $15 \mathrm{~s}$. The separated dsDNA never reverted to form the $\mathrm{X}$-shape. This observation suggests that the resolution of the GQ/i-motif duplex was induced by the GQ formation followed by separation of strands.

Next, using the acidic condition, we examined the separation of the dsDNA in the DNA frame. The structural conversion from the X-shaped structure to the two separated strands was observed at $15 \mathrm{~s}$ (Figure 4e). The separated dsDNA also never reverted to form the X-shape, which suggests that the resolution of the GQ/i-motif duplex can also be induced by the i-motif formation and the subsequent separation of the strands occurred.

Finally, we examined the dynamic movement of DNA strands in the acidic condition with $\mathrm{K}^{+}$. We observed the clear structural conversion from the X-shaped structure to the two separated strands at $10 \mathrm{~s}$ (Figure 4f). The separated dsDNA appeared as straight strands because both strands should form the GQ and i-motif structures. This also suggests that both the GQ and imotif formation strongly induced the resolution of the GQ/i-motif duplex. These results indicate that the dynamic dissociation of the GQ/i-motif duplex induced by the GQ and i-motif formation can be observed at the single-molecule resolution using this topologically controlled system and high-speed AFM. Although it is still difficult to obtain the time-constant for the resolution of the duplex, the resolution occurred within 5 s during one-time AFM scanning for this high-speed AFM observation. DNA frame should easily loosen the GQ/i-motif duplex compared with the usual dsDNA and alter the equilibirum between the dsDNA and ssDNAs, so that the DNA frame can promote the dissociation of the dsDNA into ssDNAs, and the formed ssDNAs subsequently changed into the stable GQ and i-motif depending on the buffer conditions.

The reverse hybridization to form the GQ/i-motif dsDNA (State 1 in Figure 4 and State D in Figure 3) from the separated GQ structure and i-motif strand (State 2 in Figure 4 and State C in Figure 3) was imaged by high-speed AFM by removing $\mathrm{K}^{+}$(Figure $3 \mathrm{~d}$ ). The reversible formation and dissociation of the GQ/i-motif dsDNA can be manipulated by the stepwise operations. 


\section{Conclusions}

We have demonstrated the formation and dissociation of dsDNA containing the GQ sequence and the counterpart i-motif sequence in the DNA nanostructure and observed them at the singlemolecule level. We performed sequential manipulation of DNA strands in the DNA frame and successfully prepared the topologically controlled GQ/i-motif dsDNA. Using the toehold strand and the addition and removal of $\mathrm{K}^{+}$, the topologically controlled $\mathrm{GQ} / \mathrm{i}$-motif dsDNA in the DNA frame was obtained in high yield. Using this prepared GQ/i-motif duplex, the dsDNA was resolved into the GQ and the i-motif by addition of $\mathrm{K}^{+}$and/or under an acidic condition as indicated in the promoter region. The dissociation of dsDNA after the formation of the GQ and imotif was monitored by high-speed AFM, and the dissociation of dsDNA containing the GQand i-motif-forming sequence was controlled in the DNA frame. The results obtained in this study show that the GQ/i-motif duplex system constructed in the DNA frame can be a structural model for studying the dynamic GQ and i-motif formation, which is involved in the regulation of gene expression in the promoter region.

\section{Experimental Section}

Materials. Single stranded M13mp18 viral DNA was purchased from New England Biolabs, Inc (Ipswich, MA). All the staple DNAs for the DNA frame were purchased from Eurofins Genomics (Tokyo, Japan). The DNA strands for incorporation into the DNA frame were purchased from Japan Bio Services (Saitama, Japan). Gel-filtration column was prepared with sephacryl-400 (GE Healthcare) with the experimental buffer. Superfiltration was performed using a superfiltration column (Amicon). Circular dichroism (CD) spectra were obtained using JASCO J-1100 spectropolarimeter (Tokyo, Japan) in a solution containing DNA strands (5 $\mu \mathrm{M})$, $10 \mathrm{mM}$ Tris (pH 7.6) or MES (pH 5.5) buffer, $12.5 \mathrm{mM} \mathrm{MgCl}_{2}$, and $1 \mathrm{mM}$ EDTA in the presence or absence of $50 \mathrm{mM} \mathrm{KCl}$.

Single-molecule GQ and i-motif formation in the DNA frame. DNA origami frame was prepared by annealing the solution containing M13mp18 DNA (10 nM), staple DNA 
strands (4 eq), $20 \mathrm{mM}$ Tris- $\mathrm{HCl}$ (pH 7.6), $12.5 \mathrm{mM} \mathrm{MgCl}_{2}, 1 \mathrm{mM}$ EDTA, and $50 \mathrm{mM} \mathrm{KCl}$ from 85 to $15^{\circ} \mathrm{C}$ at a rate $-1.0^{\circ} \mathrm{C} / \mathrm{min}$. The DNA strands containing divided GQ or i-motif sequence for introduction to the top side (a-b connector) and the bottom side (c-d connector) were also prepared using the same condition with that of the DNA frame. The pre-assembled strands (5 eq) were incorporated into the DNA frame by re-annealing the solution from 40 (kept for $10 \mathrm{~min}$ ) to $15^{\circ} \mathrm{C}$ at a rate of $-0.5^{\circ} \mathrm{C} / \mathrm{min}$. For the GQ formation, the sample $(2 \mu \mathrm{L})$ was added to the observation buffer containing $50 \mathrm{mM} \mathrm{KCl}$. In the case of the i-motif formation, the sample (2 $\mu \mathrm{L}$ ) was added to the $\mathrm{pH} 5.5$ observation buffer.

The buffer conditions for the AFM observation are as follows; the neutral condition with $\mathrm{K}^{+}$ buffer: $10 \mathrm{mM}$ Tris ( $\mathrm{pH} 7.6), 12.5 \mathrm{mM} \mathrm{MgCl}, 50 \mathrm{mM} \mathrm{KCl}$; the acidic condition buffer: $10 \mathrm{mM}$ MES (pH 5.5), $12.5 \mathrm{mM} \mathrm{MgCl}$; acidic condition with $\mathrm{K}^{+}$buffer: $10 \mathrm{mM} \mathrm{MES}$ (pH 5.5), $12.5 \mathrm{mM}$ $\mathrm{MgCl}_{2}, 50 \mathrm{mM} \mathrm{KCl}$.

Preparation of the GQ/i-motif double-stranded DNA in the DNA frame. The DNA strands containing GQ sequence for the top side and that containing i-motif sequence for the bottom side were also prepared using the same condition with that of the DNA frame. First, introduction of the i-motif-containing strand ( $5 \mathrm{eq})$ covered with the toehold-protecting sequence into the DNA frame was carried out by re-annealing the solution from 40 (kept for $10 \mathrm{~min}$ ) to 15 ${ }^{\circ} \mathrm{C}$ at a rate of $-0.5^{\circ} \mathrm{C} / \mathrm{min}$. Then the GQ-containing strand (5 eq) was introduced into the top side of the DNA frame (a-b connector) with the annealing step from 30 (stay for $6 \mathrm{~min}$ ) to $12{ }^{\circ} \mathrm{C}$ at a rate of $-0.4{ }^{\circ} \mathrm{C} / \mathrm{min}$. After that, the two strands attached DNA frame was purified by sephacyl S400 gel-filtration column. The sequences for incorporated strands are described in the supporting information. For the preparation of the GQ/i-motif dsDNA, we first removed the toeholdprotecting sequence in the bottom side by adding the release strand containing complementary to the toehold-protecting sequence $(10 \mathrm{eq})$. Then the samples were desalted twice by a centrifugal filter (100 k NMWL, Millipore Amicon) at rt for 10 min with the buffer which contained $10 \mathrm{mM}$ Tris- $\mathrm{HCl}\left(\mathrm{pH}\right.$ 7.6), $1 \mathrm{mM}$ EDTA, $12.5 \mathrm{mM} \mathrm{MgCl}_{2}$ and the samples were incubated at $\mathrm{rt}$ for $1 \mathrm{~h}$. 
The desalted sample $(2 \mu \mathrm{L})$ was added to $28 \mu \mathrm{L}$ of the buffer for the AFM observation, and incubated at $\mathrm{rt}$ for $1 \mathrm{~h}$. The states of DNA strands in the DNA frames in all the steps were checked by AFM observation.

AFM imaging. Imaging was performed using a high-speed AFM (Nano Live Vision, RIBM, Tsukuba, Japan). The sample ( $2 \mu \mathrm{L})$ was deposited onto a freshly cleaved mica, kept for $5 \mathrm{~min}$, and then rinsed with the buffer. The sample was imaged in the observation buffer solution at $\mathrm{rt}$ using a small cantilever (BL-AC10EGS, Olympus Corporation, Tokyo, Japan) with a spring constant of $0.1-0.2 \mathrm{~N} / \mathrm{m}$ with a resonant frequency of $400-1000 \mathrm{kHz}$ in water. The AFM images were obtained at a scan rate of 0.2-1.0 frames per second (fps). The data were collected by counting 50 to 150 DNA frames from AFM images for each experiment.

\section{ASSOCIATED CONTENT}

\section{Supporting Information.}

DNA sequences, additional experiments, and additional AFM images. This material is available free of charge via the Internet at http://pubs.acs.org.

\section{AUTHOR INFORMATION}

Corresponding Author

endo@kuchem.kyoto-u.ac.jp; hs@kuchem.kyoto-u.ac.jp.

\section{ACKNOWLEDGMENT}

This work was supported by Core Research for Evolutional Science and Technology (CREST) of JST and JSPS KAKENHI (Grant Numbers 15H03837, 24104002, 24225005, 26620133). Financial supports from the Sekisui Chemical Research Grant and the Kurata Memorial Hitachi 
Science and Technology Foundation to ME are also acknowledged. XX was supported by the National Science Foundation of China (No. 21432008).

\section{REFERENCES}

1. Huppert, J. L.; Balasubramanian, S., G-quadruplexes in promoters throughout the human genome. NucleicAcids Res. 2007, 35, 406-413.

2. Siddiqui-Jain, A.; Grand, C. L.; Bearss, D. J.; Hurley, L. H., Direct evidence for a Gquadruplex in a promoter region and its targeting with a small molecule to repress c-MYC transcription. Proc. Natl. Acad. Sci. USA 2002, 99, 11593-11598.

3. Gehring, K.; Leroy, J. L.; Gueron, M., A tetrameric DNA structure with protonated cytosine.cytosine base pairs. Nature 1993, 363, 561-565.

4. Xu, Y.; Sugiyama, H., Formation of the G-quadruplex and i-motif structures in retinoblastoma susceptibility genes (Rb). NucleicAcids Res. 2006, 34, 949-954.

5. Sun, D.; Hurley, L. H., The importance of negative superhelicity in inducing the formation of G-quadruplex and i-motif structures in the c-Myc promoter: implications for drug targeting and control of gene expression. J. Med. Chem. 2009, 52, 2863-2874.

6. Dhakal, S.; Schonhoft, J. D.; Koirala, D.; Yu, Z.; Basu, S.; Mao, H., Coexistence of an ILPR i-motif and a partially folded structure with comparable mechanical stability revealed at the single-molecule level. J. Am. Chem. Soc. 2010, 132, 8991-8997.

7. $\quad$ Dhakal, S.; Yu, Z.; Konik, R.; Cui, Y.; Koirala, D.; Mao, H., G-quadruplex and i-motif are mutually exclusive in ILPR double-stranded DNA. Biophys J. 2012, 102, 2575-2584.

8. $\quad$ Guo, K.; Pourpak, A.; Beetz-Rogers, K.; Gokhale, V.; Sun, D.; Hurley, L. H., Formation of pseudosymmetrical G-quadruplex and i-motif structures in the proximal promoter region of the RET oncogene. J. Am. Chem. Soc. 2007, 129, 10220-10228.

9. Miyoshi, D.; Matsumura, S.; Nakano, S.; Sugimoto, N., Duplex dissociation of telomere DNAs induced by molecular crowding. J. Am. Chem. Soc. 2004, 126, 165-169.

10. Yu, Z.; Schonhoft, J. D.; Dhakal, S.; Bajracharya, R.; Hegde, R.; Basu, S.; Mao, H., ILPR G-quadruplexes formed in seconds demonstrate high mechanical stabilities. J. Am. Chem. Soc. 2009, 131, 1876-1882.

11. Liu, X.; Lu, C. H.; Willner, I., Switchable reconfiguration of nucleic acid nanostructures by stimuli-responsive DNA machines. Acc. Chem. Res. 2014, 47, 1673-1680.

12. Wang, F.; Liu, X.; Willner, I., DNA switches: from principles to applications. Angew. Chem. Int. Ed. 2015, 54, 1098-1129.

13. Krishnan, Y.; Simmel, F. C., Nucleic acid based molecular devices. Angew. Chem. Int. Ed. 2011, 50, 3124-3156.

14. (a) Endo, M.; Sugiyama, H., Single-molecule imaging of dynamic motions of biomolecules in DNA origami nanostructures using high-speed atomic force microscopy. Acc. Chem. Res. 2014, 47, 1645-1653; (b) Rajendran, A.; Endo, M.; Sugiyama, H., State-of-the-art high-speed atomic force microscopy for investigation of single-molecular dynamics of proteins. Chem. Rev. 2014, 114, 1493-1520.

15. (a) Sannohe, Y.; Endo, M.; Katsuda, Y.; Hidaka, K.; Sugiyama, H., Visualization of dynamic conformational switching of the G-quadruplex in a DNA nanostructure. J. Am. Chem. Soc. 2010, 132, 16311-16313; (b) Rajendran, A.; Endo, M.; Hidaka, K.; Tran, P. L.; Mergny, J. L.; Sugiyama, H., Controlling the stoichiometry and strand polarity of a tetramolecular Gquadruplex structure by using a DNA origami frame. NucleicAacids Res. 2013, 41, 8738-8747; (c) Rajendran, A.; Endo, M.; Hidaka, K.; Sugiyama, H., Direct and single-molecule visualization of the solution-state structures of G-hairpin and G-triplex intermediates. Angew. Chem. Int. Ed. $2014,53,4107-4112$. 
16. (a) Rajendran, A.; Endo, M.; Hidaka, K.; Sugiyama, H., Direct and real-time observation of rotary movement of a DNA nanomechanical device. J. Am. Chem. Soc. 2013, 135, 11171123; (b) Endo, M.; Inoue, M.; Suzuki, Y.; Masui, C.; Morinaga, H.; Hidaka, K.; Sugiyama, H., Regulation of B-Z conformational transition and complex formation with a Z-form binding protein by introduction of constraint to double-stranded DNA by using a DNA nanoscaffold. Chem. Eur. J. 2013, 19, 16887-16890.

17. (a) Liang, X.; Mochizuki, T.; Asanuma, H., A supra-photoswitch involving sandwiched DNA base pairs and azobenzenes for light-driven nanostructures and nanodevices. Small 2009, 5, 1761-1768; (b) Endo, M.; Yang, Y.; Suzuki, Y.; Hidaka, K.; Sugiyama, H., Single-molecule visualization of the hybridization and dissociation of photoresponsive oligonucleotides and their reversible switching behavior in a DNA nanostructure. Angew. Chem. Int. Ed. 2012, 51, 1051810522. (c) Yang, Y.; Endo, M.; Suzuki, Y.; Hidaka, K.; Sugiyama, H., Direct observation of the dual-switching behaviors corresponding to the state transition in a DNA nanoframe. Chem. Commun. 2014, 50, 4211-4213;

18. (a) Endo, M.; Katsuda, Y.; Hidaka, K.; Sugiyama, H., Regulation of DNA methylation using different tensions of double strands constructed in a defined DNA nanostructure. J. Am. Chem. Soc. 2010, 132, 1592-1597; (b) Endo, M.; Katsuda, Y.; Hidaka, K.; Sugiyama, H., A versatile DNA nanochip for direct analysis of DNA base-excision repair. Angew. Chem. Int. Ed. 2010, 49, 9412-9416; (c) Suzuki, Y.; Endo, M.; Katsuda, Y.; Ou, K.; Hidaka, K.; Sugiyama, H., DNA origami based visualization system for studying site-specific recombination events. J. Am. Chem. Soc. 2014, 136, 211-218; (d) Suzuki, Y.; Endo, M.; Canas, C.; Ayora, S.; Alonso, J. C.; Sugiyama, H.; Takeyasu, K., Direct analysis of Holliday junction resolving enzyme in a DNA origami nanostructure. NucleicAcids Res. 2014, 42, 7421-7428.

19. Schonhoft, J. D.; Bajracharya, R.; Dhakal, S.; Yu, Z.; Mao, H.; Basu, S., Direct experimental evidence for quadruplex-quadruplex interaction within the human ILPR. NucleicAcids Res. 2009, 37, 3310-3320. 
(a)

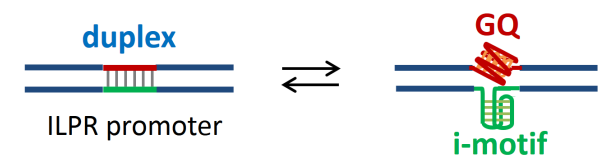

(b)
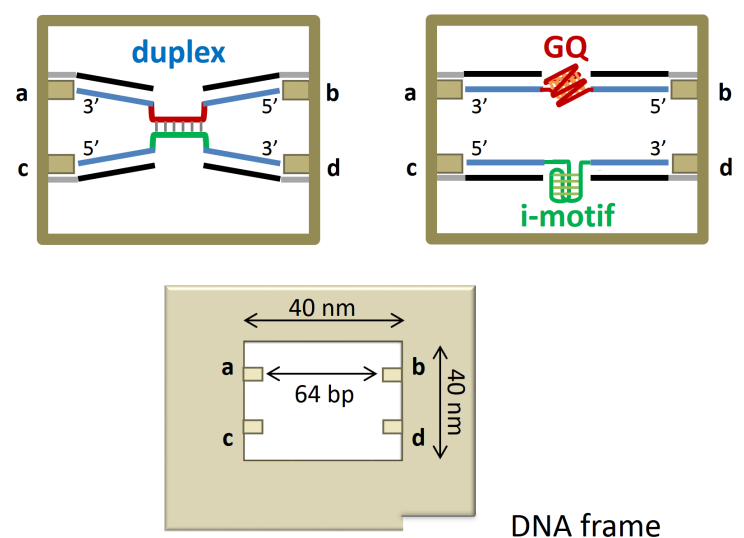

(c)

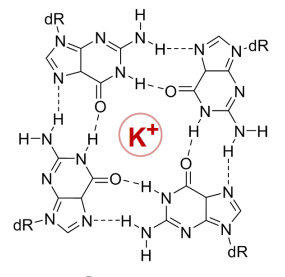

G-quartet

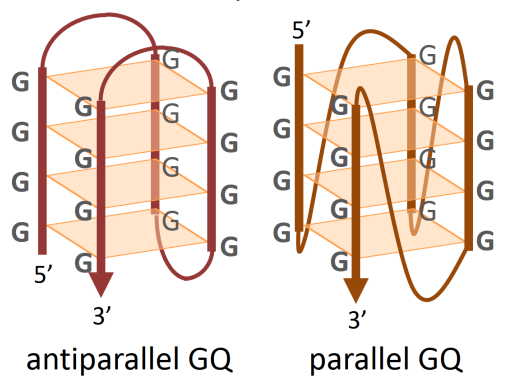

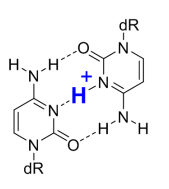

$\mathrm{C}^{-} \mathrm{C}^{+}$pair

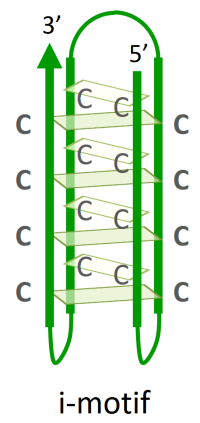

Figure 1. Single-molecule observation of the GQ and i-motif formation from a duplex in the DNA frame. (a) The ILPR promoter region is thought to be separated into the GQ and i-motif in the regulation of transcription. (b) The GQ and i-motif forming core sequences of ILPR promoter are introduced into the DNA frame shown below for observation of the GQ and i-motif under various conditions. (c) G-quadruplex (antiparallel and parallel GQ) and i-motif structure. For the formation of GQ and i-motif, $\mathrm{K}^{+}$and acidic condition are required, respectively. 
(a)

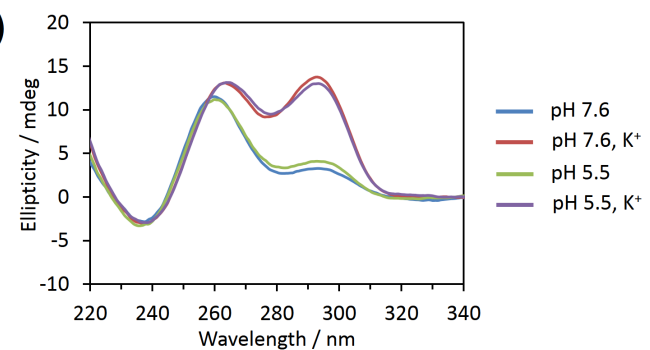

(b)

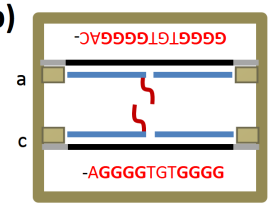

pH 7.6

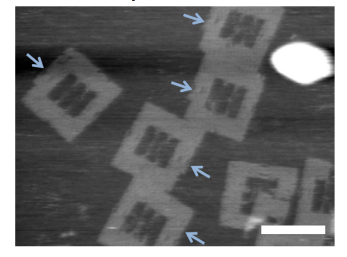

pH 5.5
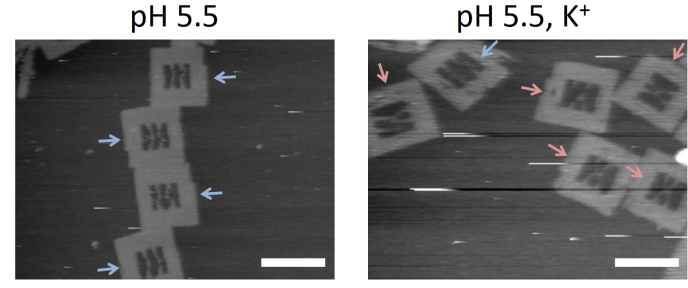

(c)

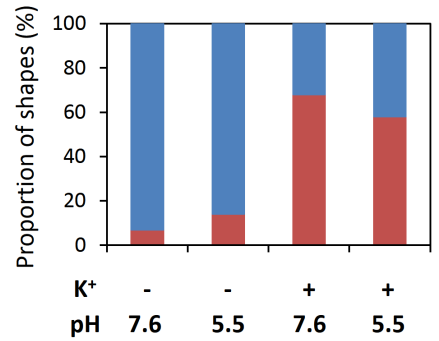

(d)

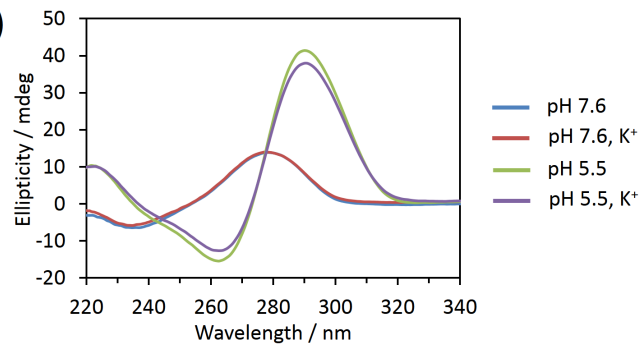

(e)

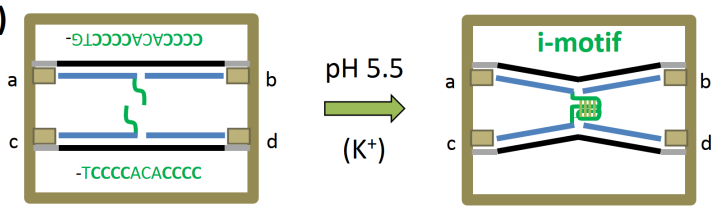

pH 7.6

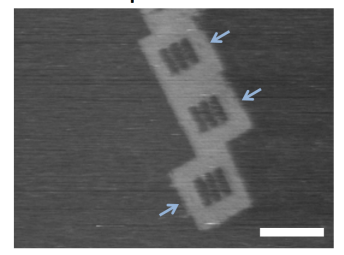

$\mathrm{pH} 5.5$
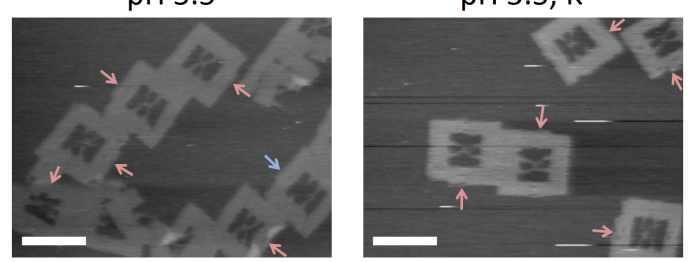

(f)

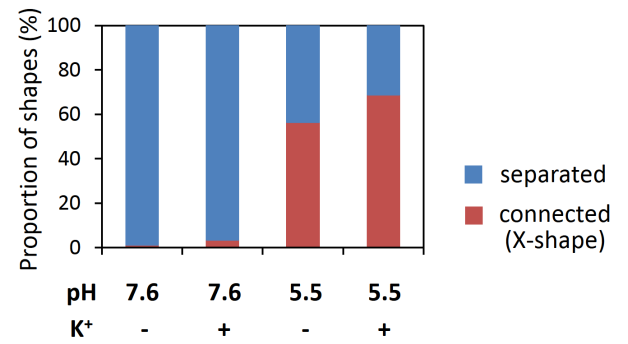

Figure 2. Single-molecule GQ and i-motif formation in the observation conditions. (a) CD spectra of GQ in the various conditions. (b) AFM images of DNA frames containing G-tracts for the interstrand GQ formation in the presence of $\mathrm{K}^{+}$. Blue and red arrows indicate the separated and connected (X-shaped) strands, respectively. Scale bars $100 \mathrm{~nm}$. (c) Summary of the interstrand GQ formation in the DNA frame. (d) CD spectra of i-motif in the various conditions. (e) AFM images of DNA frames containing C-tracts for the interstrand i-motif formation in the acidic condition. Blue and red arrows indicate the separated and connected (X-shaped) strands, respectively. (f) Summary of the interstrand i-motif formation in the DNA frame. 


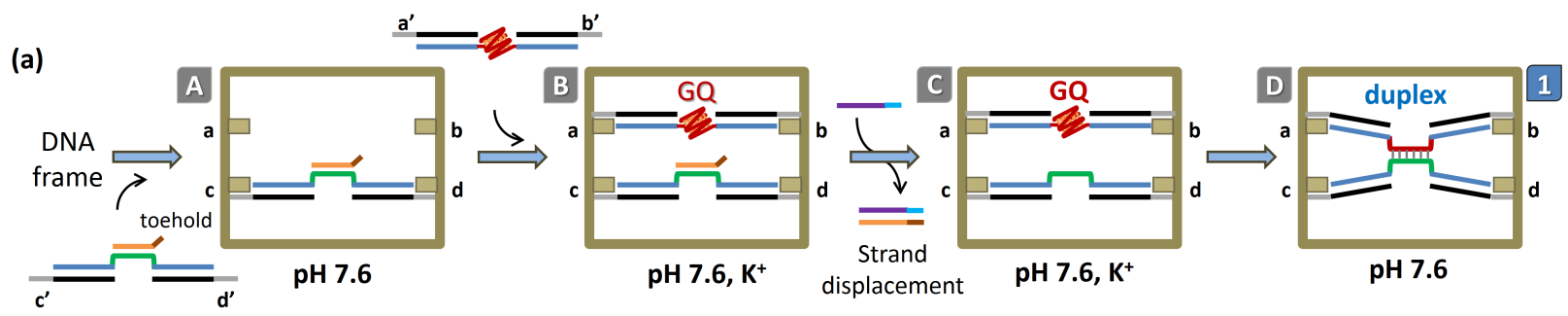

(b)
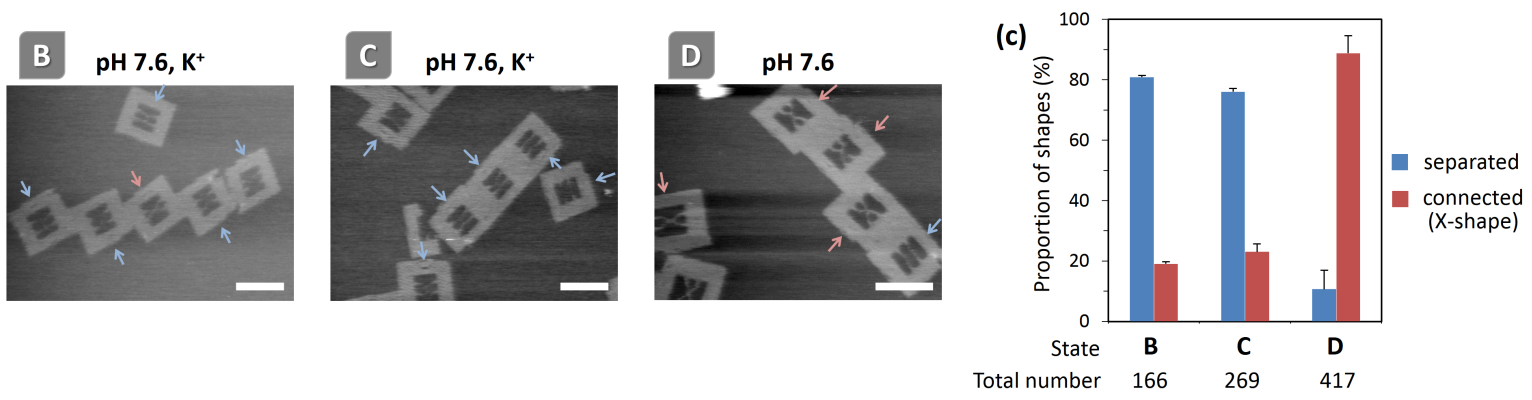

(d)
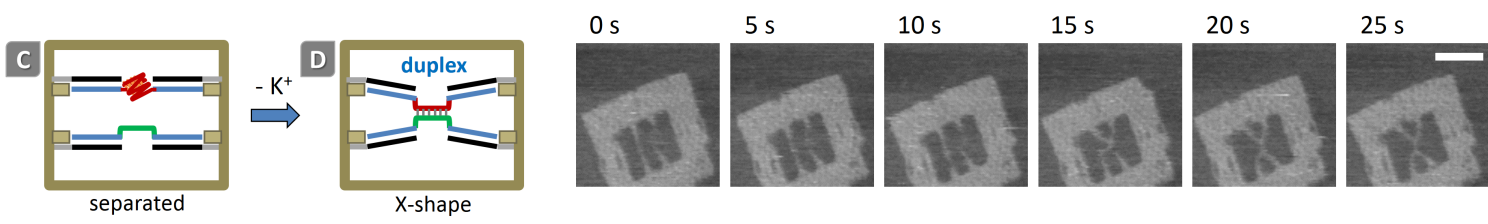

Figure 3. Operation to prepare topologically controlled GQ/i-motif dsDNA in the DNA frame.

First, a DNA strand that had its i-motif sequence [5'- CCCCACACCCCTGTCCCCACACCCC-

$3^{\prime}$ ] covered with toehold-containing complementary strand was incorporated into the bottom side

(c and d connector) in the DNA frame (State A). Second, a DNA strand that formed the GQ [5'-

GGGGTGTGGGGACAGGGGTGTGGGG-3'] was incorporated into the top side (a and b connector) in the DNA frame (State B). Third, the complementary toehold strand was introduced to uncover the $\mathrm{i}$-motif sequence (State $\mathrm{C}$ ). Fourth, $\mathrm{K}^{+}$was removed to hybridize two strands to form dsDNA (State D). (b) AFM images of the structures, states B, C, and D. Blue and red arrows indicate the separated and connected (X-shaped) strands, respectively. Scale bars $100 \mathrm{~nm}$. (c) Summarized results of the formation of separated and connected DNA strands in the DNA frame. Blue and red bars indicate the separated and connected (X-shaped) strands, respectively. The values (mean \pm SD) were obtained from three independent experiments. (d) Single-molecule 
observation of GQ and i-motif formation from the duplex in the DNA frame. Time-lapsed AFM images of the formation of the dsDNA induced by removal of $\mathrm{K}^{+}$. Time $0 \mathrm{~s}$ is an arbitrary time during the AFM scanning. Scanning rate, 0.2 frames/s. Scale bar $50 \mathrm{~nm}$. 
(a)

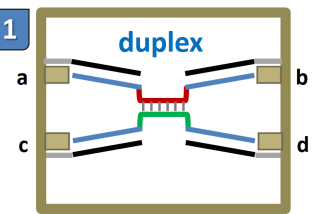

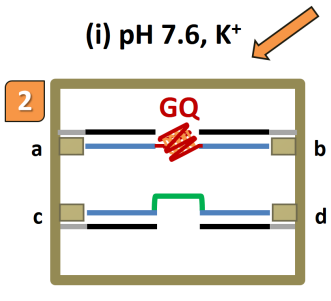

$\mathrm{pH} 7.6, \mathrm{~K}^{+}$

(b)

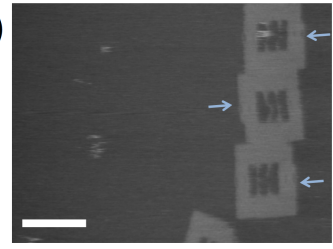

(d)

$1 \Longrightarrow 2$

(i) $\mathrm{pH} 7.6, \mathrm{~K}^{+}$

(e)

$1 \Rightarrow 3$

(ii) $\mathrm{pH} 5.5$

(f)

$1 \longrightarrow 4$

(iii) pH 5.5, $\mathrm{K}^{+}$
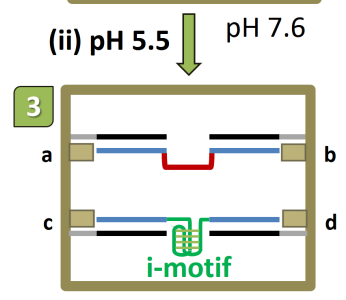

pH 5.5
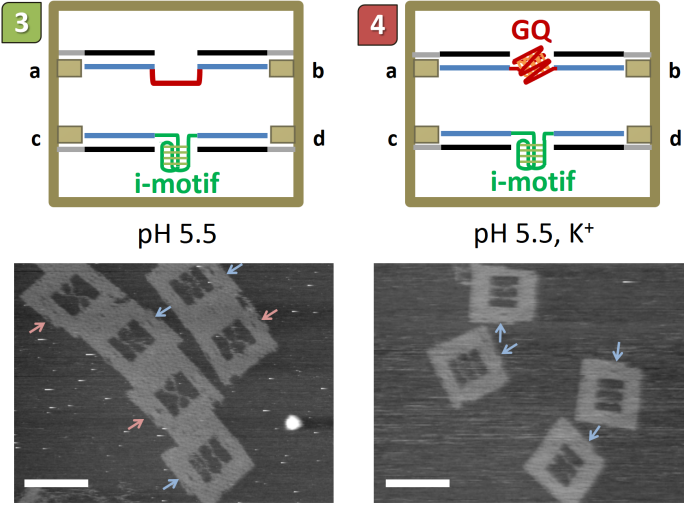

$\mathrm{pH} 5.5, \mathrm{~K}^{+}$

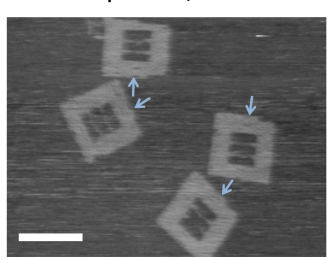

(c)
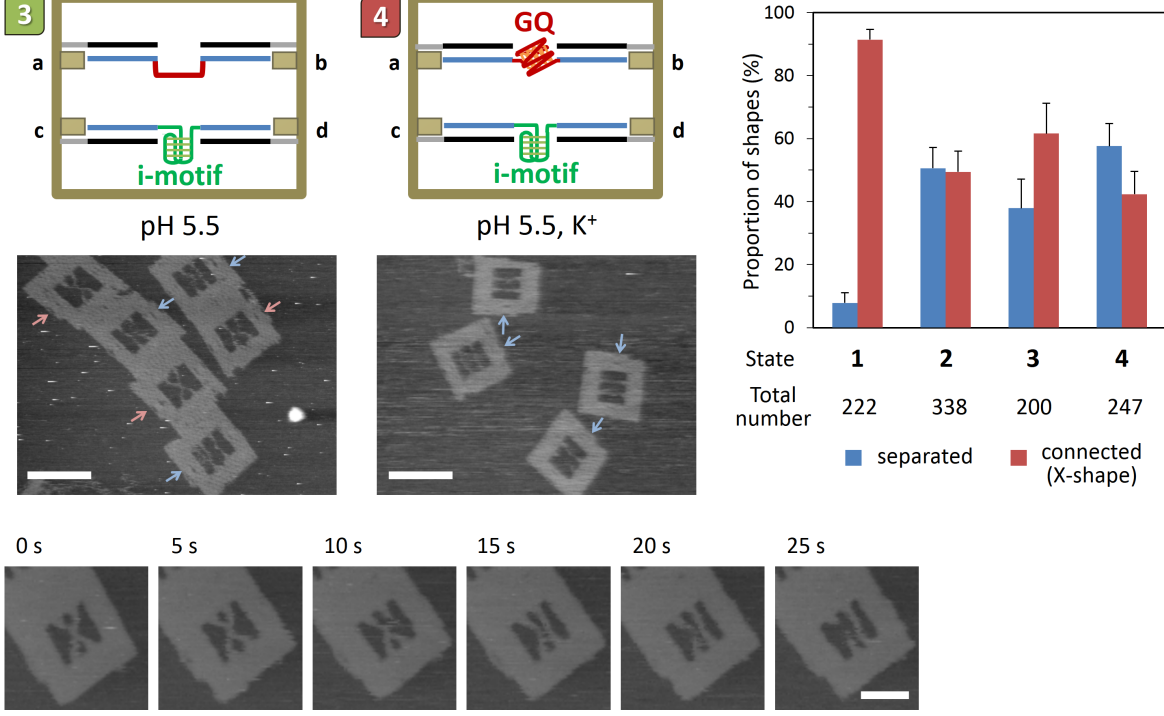

$25 \mathrm{~s}$

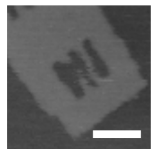

$25 \mathrm{~s}$

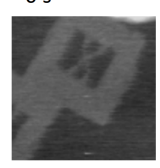

$5 \mathrm{~s}$

$10 \mathrm{~s}$

$15 \mathrm{~s}$

$20 \mathrm{~s}$

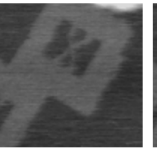

$5 \mathrm{~s}$
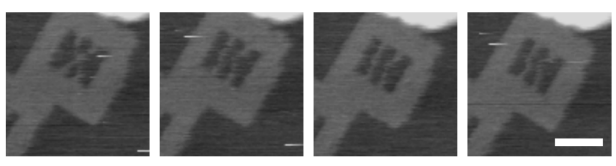

$10 \mathrm{~s}$

$15 \mathrm{~s}$

$20 \mathrm{~s}$

$25 \mathrm{~s}$
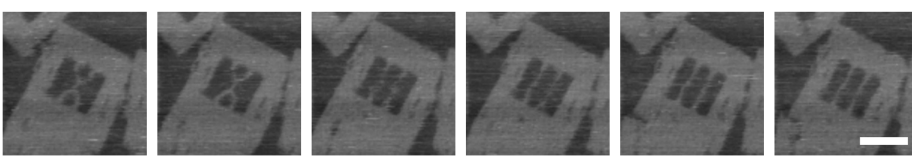

Figure 4. Resolution of the prepared GQ/i-motif dsDNA in the DNA frame into the Gquadruplex and i-motif structure. (a) Three operations were used to change the states of DNA strands: (i) $\mathrm{pH} 7.6, \mathrm{~K}^{+}$for the GQ formation (State 1 to 2); (ii) $\mathrm{pH} 5.5$ for the i-motif formation (State 1 to 3); and (iii) $\mathrm{pH} 5.5, \mathrm{~K}^{+}$for the GQ and i-motif formation (State 1 to 4). (b) AFM images for the three conditions for formation of States 2-4. Blue and red arrows indicate the separated and connected (X-shape) strands, respectively. Scale bars $100 \mathrm{~nm}$. (c) Summarized results of formation of separated and contacted DNA strands in the DNA frame using these operations. The values (mean $\pm \mathrm{SD}$ ) were obtained from three independent experiments. Timelapsed high-speed AFM images for the separation of the GQ/i-motif dsDNA induced by the $\mathrm{K}^{+}$ 
and acidic condition in the DNA frame. (d) Lapsed images of the dissociation of duplex in the presence of $\mathrm{K}^{+}$. (e) Lapsed images of the dissociation of duplex under the acidic condition. (f) Lapsed images of the dissociation of duplex in the presence of $\mathrm{K}^{+}$under the acidic condition. Time $0 \mathrm{~s}$ is an arbitrary time during the A FM scanning. Scanning rate, 0.2 frame/s. Scale bars 50 $\mathrm{nm}$. 
Graphical Abstract

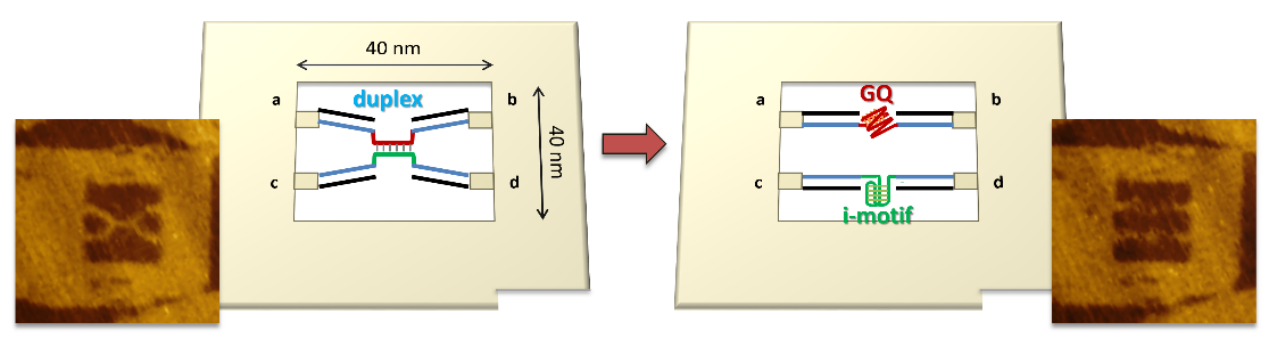


Supporting Information

\section{Single-Molecule Manipulation of the Duplex Formation and Dissociation at G-quadruplex / i-motif Site in the DNA Nanostructure}

Masayuki Endo, ${ }^{* \dagger}$ Xiwen Xing, ${ }^{\star \top}$ Xiang Zhou, ${ }^{\llbracket}$ Tomoko Emura, ${ }^{\ddagger}$ Kumi Hidaka, ${ }^{\ddagger}$ Bodin Tuesuwan, Hiroshi Sugiyama*t\$

${ }^{\dagger}$ Institute for Integrated Cell-Material Sciences (WPI-iCeMS), Kyoto University, Yoshida-ushinomiyacho, Sakyo-ku, Kyoto 606-8501, Japan

¿Department of Chemistry, Graduate School of Science, Kyoto University, Kitashirakawa-oiwakecho, Sakyo-ku, Kyoto 606-8502, Japan

${ }^{\S}$ CREST, Japan Science and Technology Corporation (JST), Sanbancho, Chiyoda-ku, Tokyo 102-0075, Japan

${ }^{\top}$ College of Chemistry and Molecular Sciences, Key Laboratory of Biomedical Polymers of Ministry of Education, Wuhan University, Wuhan, Hubei 430072, P. R. China

'Department of Food and Pharmaceutical Chemistry, Faculty of Pharmaceutical Sciences, Chulalongkorn University, Bangkok 10330, Thailand

\footnotetext{
*Authors to whom correspondence should be addressed.

endo@kuchem.kyoto-u.ac.jp (ME); hs@kuchem.kyoto-u.ac.jp (HS)
} 


\section{$64 \mathrm{bp}$}

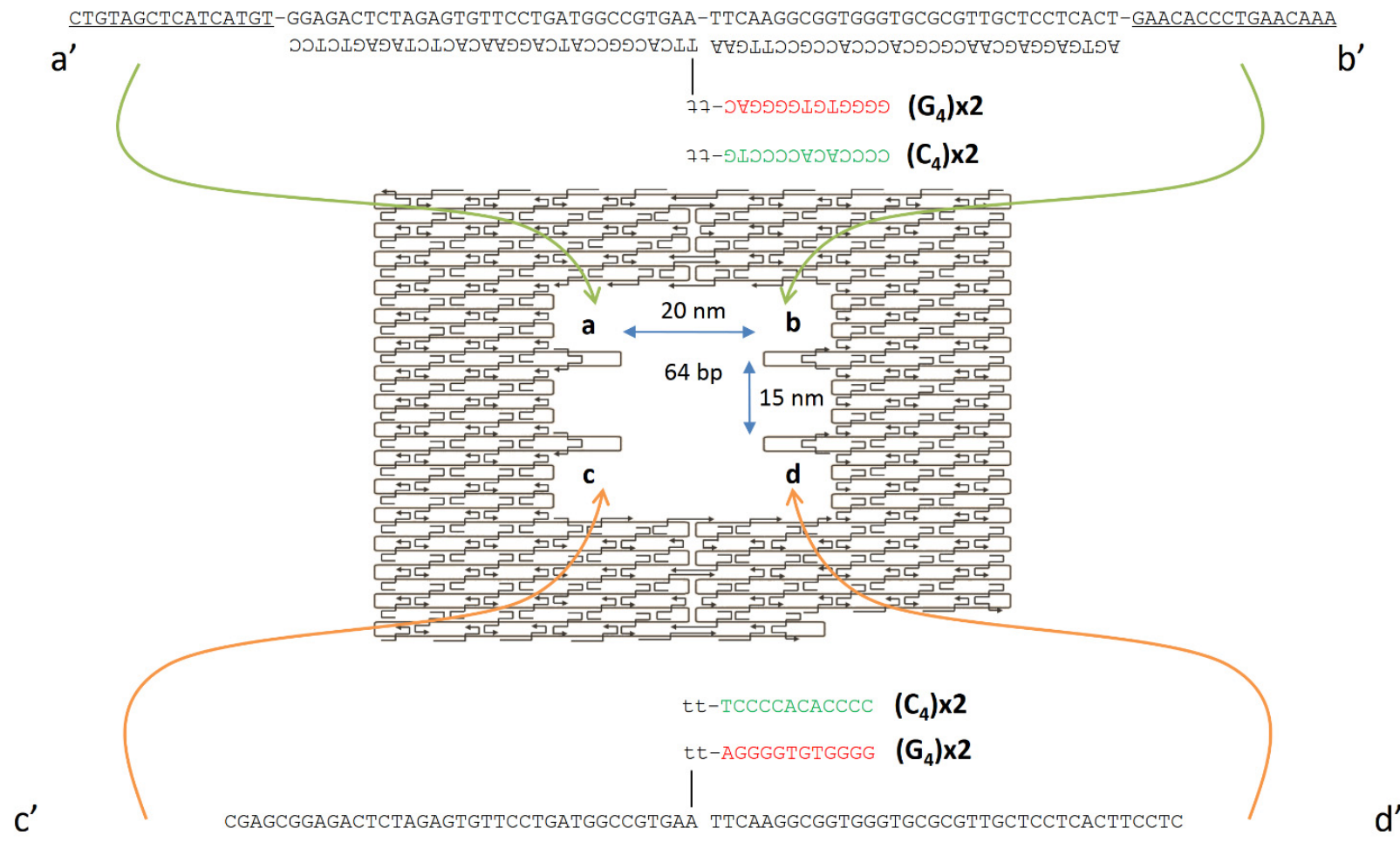

गШ

\section{$74 \mathrm{bp}$}

Figure S1. Sequences of DNA strands incorporated to the DNA frame for the interstrand G-quadruplex and i-motif formation. Divided GQ or i-motif sequence pairs were incorporated to the center of the top and bottom dsDNAs. 
(a)

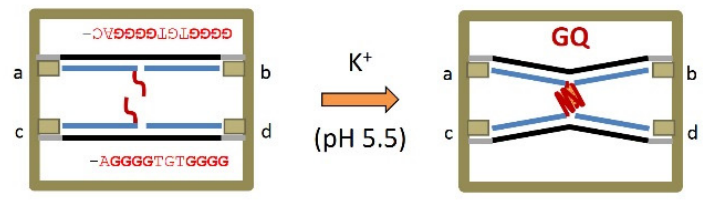

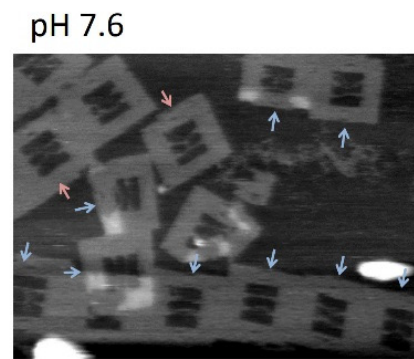

$600 \mathrm{~nm} \times 400 \mathrm{~nm}$

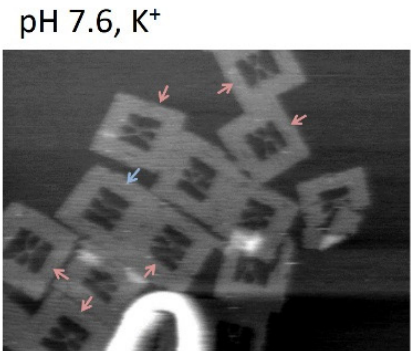

$600 \mathrm{~nm} \times 400 \mathrm{~nm}$

$\mathrm{pH} 5.5$

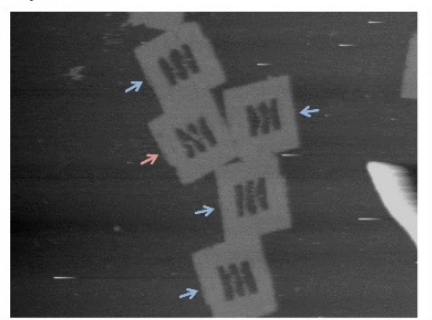

$600 \mathrm{~nm} \times 400 \mathrm{~nm}$

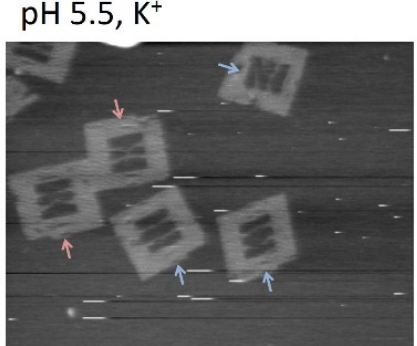

$600 \mathrm{~nm} \times 400 \mathrm{~nm}$

(b)

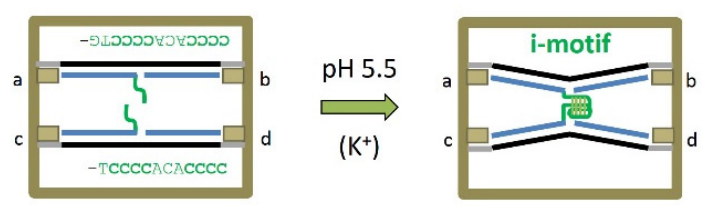

pH 7.6

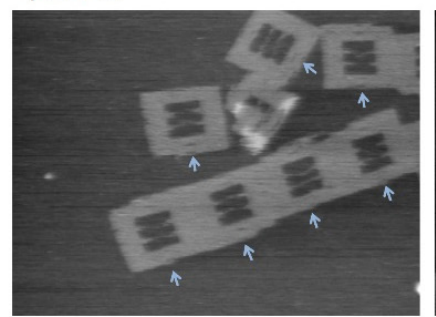

$600 \mathrm{~nm} \times 400 \mathrm{~nm}$
$\mathrm{pH} 7.6, \mathrm{~K}^{+}$

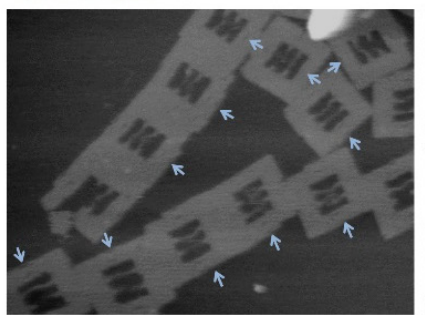

$600 \mathrm{~nm} \times 400 \mathrm{~nm}$
$\mathrm{pH} 5.5$

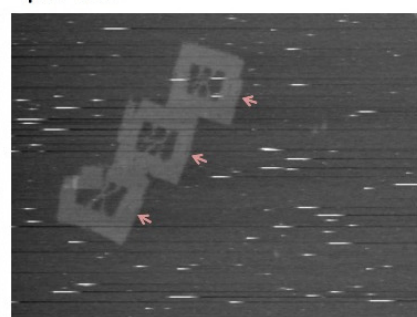

$600 \mathrm{~nm} \times 400 \mathrm{~nm}$
$\mathrm{pH} 5.5, \mathrm{~K}^{+}$

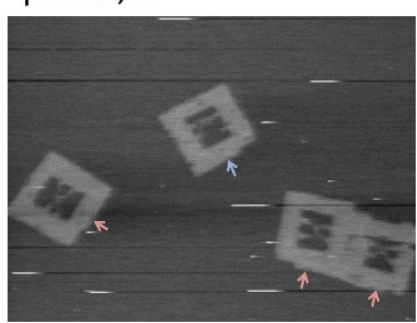

$600 \mathrm{~nm} \times 400 \mathrm{~nm}$

Figure S2. (a) AFM images of DNA frames containing G-tracts for the interstrand GQ formation.

Three conditions were used; $\mathrm{pH} 7.6$ in the absence of $\mathrm{K}^{+}$(left); $\mathrm{pH} 7.6$ with $\mathrm{K}^{+}$(center); $\mathrm{pH} 5.5$ with $\mathrm{K}^{+}$ (right). (b) AFM images of DNA frames containing C-tracts for the interstrand i-motif formation. Three conditions were used; pH7.6 (left); pH 5.5 (center); pH 5.5 with $\mathrm{K}^{+}$(right). Blue and red arrow indicate the separated and connected (X-shape) strands, respectively. 


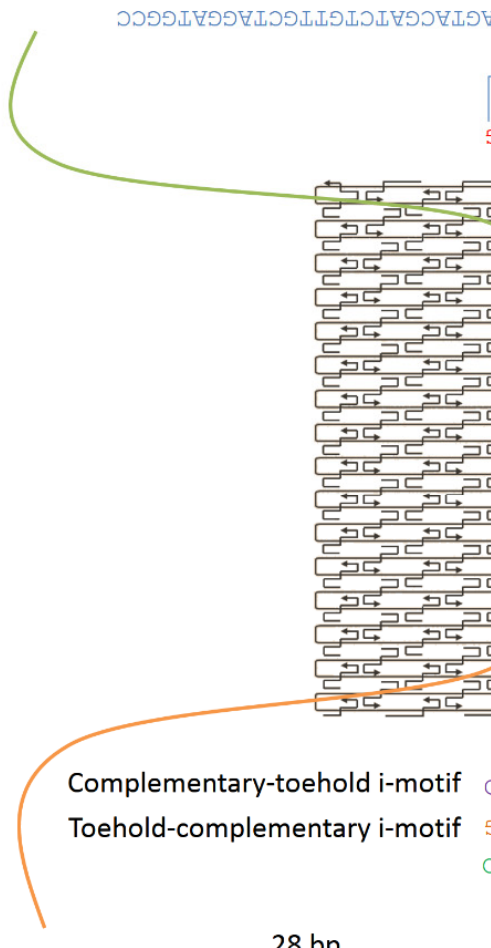

$C^{\prime}$ GGAGACTCTAGAGTGTTCCTGATGGCCG-TI

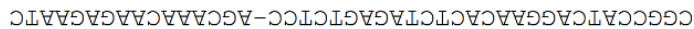

C
$28 \mathrm{bp}$

TATGCTCGAAGATGTGCGGATCGCTGGT-GAACACCCTGAACAAA

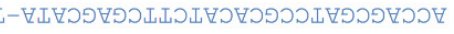

$25 \mathrm{nt}$

\section{G-quadruplex}

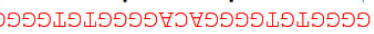

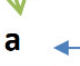

$20 \mathrm{~nm}$

$64 \mathrm{bp}$
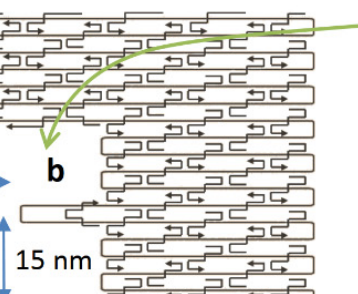

d

要

个
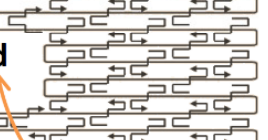

मदे

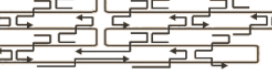

CCCACACCCCTGTCCCCACACCCC-ACTCGACGG

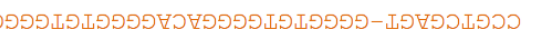

CCCCACACCCCTGTCCCCACACCCC

i-motif

$25 \mathrm{nt}$

28 bp

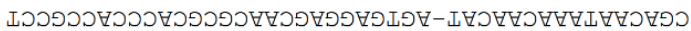

Figure S3. Sequences of DNA strands incorporated to the DNA frame for the formation of a topologically controlled G-quadruplex/i-motif duplex. First, a DNA strand which had i-motif sequence (green sequence) covered with toehold-containing complementary i-motif strand (orange sequence) was incorporated to the bottom side (c and d connector) in the DNA frame. Second, DNA strand which formed GQ (red sequence) was incorporated to the top side ( $\mathrm{a}$ and $\mathrm{b}$ connector) in the DNA frame. Third, the complementary toeholdi-motif strand (purple sequence) was introduced to uncover the toehold-complementary i-motif sequence (orange sequence). Fourth, $\mathrm{K}^{+}$was removed to form $\mathrm{GQ} / \mathrm{i}$-motif ds DNA. 
(a)

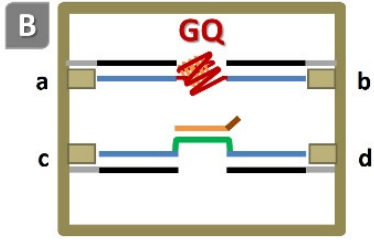

pH 7.6, $\mathrm{K}^{+}$

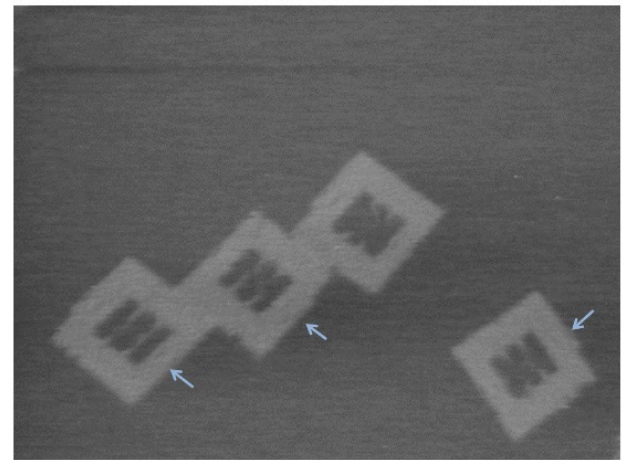

$600 \mathrm{~nm} \times 400 \mathrm{~nm}$

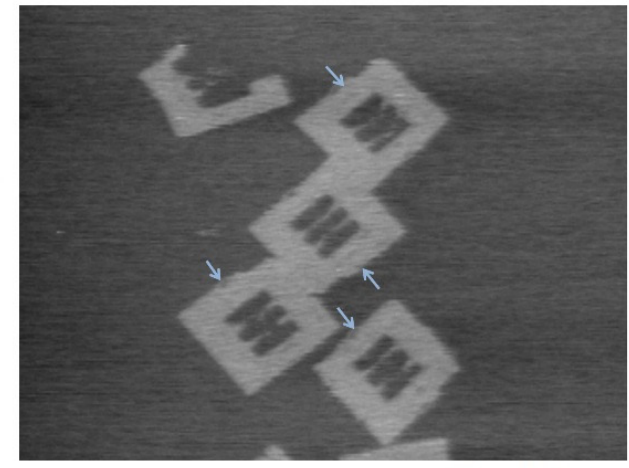

$600 \mathrm{~nm} \times 400 \mathrm{~nm}$

(c)

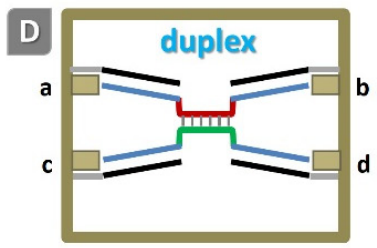

pH 7.6

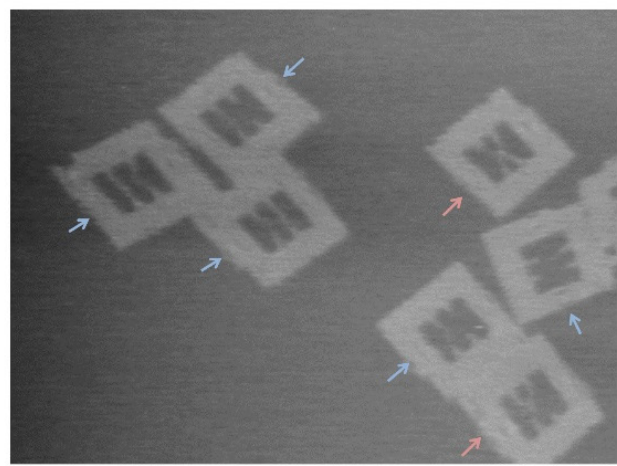

$600 \mathrm{~nm} \times 400 \mathrm{~nm}$

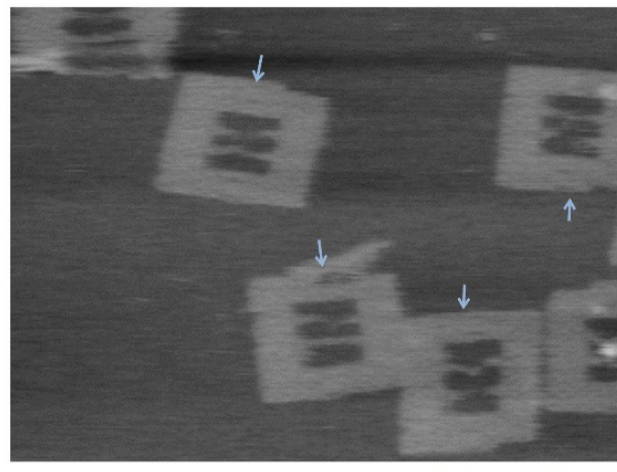

$500 \mathrm{~nm} \times 375 \mathrm{~nm}$

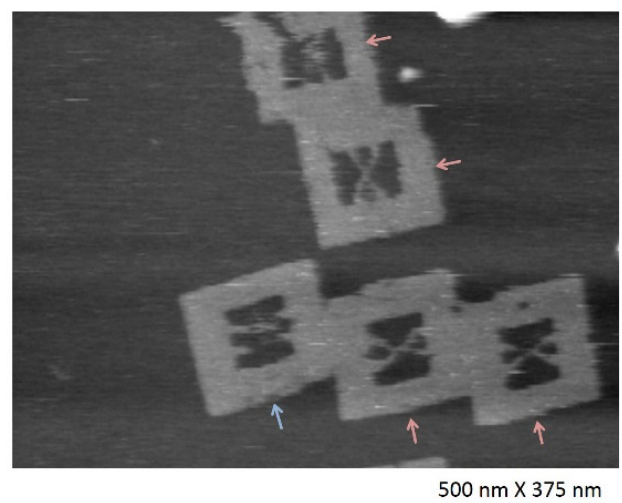

Figure S4. AFM images of DNA frames to prepare a topologically controlled dsDNA. AFM images of State B (a), State C (b), and State D (c). Blue and red arrows indicate the separated and connected (Xshaped) strands, respectively. 
(a)

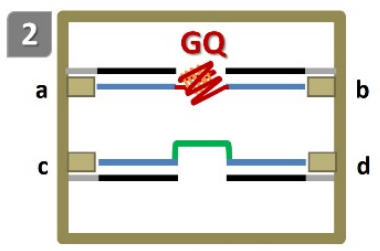

$\mathrm{pH} 7.6, \mathrm{~K}^{+}$

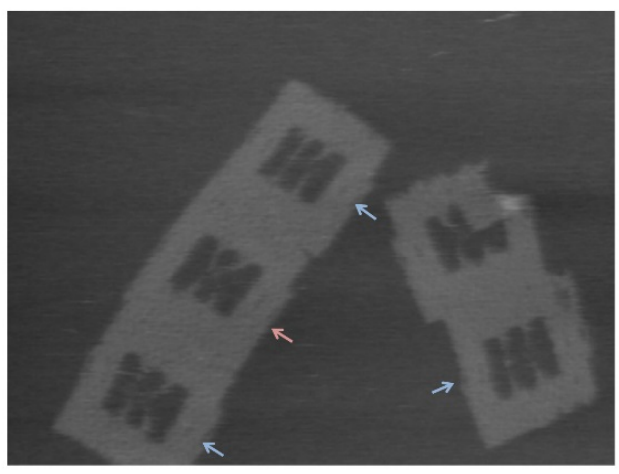

$500 \mathrm{~nm} \times 375 \mathrm{~nm}$

(b)

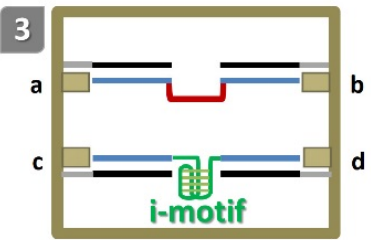

pH 5.5

(c)

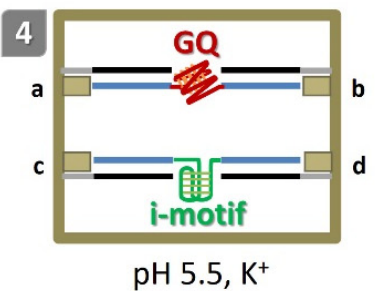

$\mathrm{pH} 5.5, \mathrm{~K}^{+}$

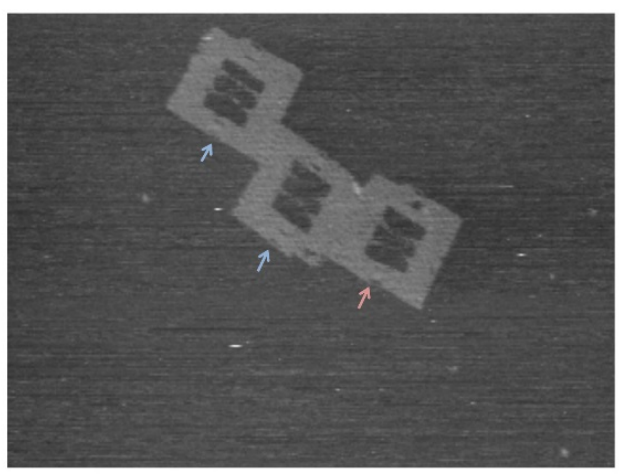

$600 \mathrm{~nm} \times 400 \mathrm{~nm}$

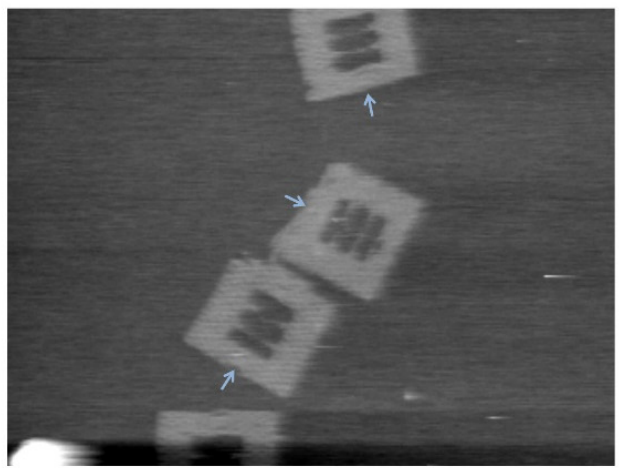

$600 \mathrm{~nm} \times 400 \mathrm{~nm}$

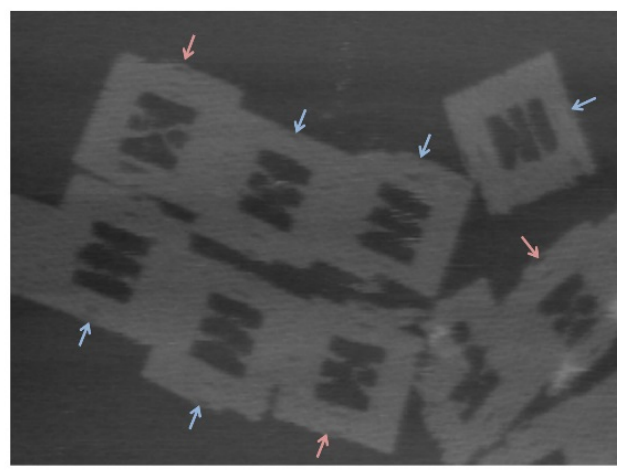

$500 \mathrm{~nm} \times 375 \mathrm{~nm}$

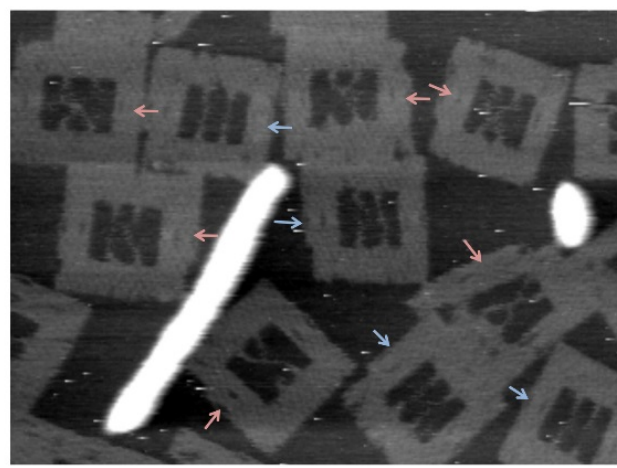

$500 \mathrm{~nm} \times 375 \mathrm{~nm}$

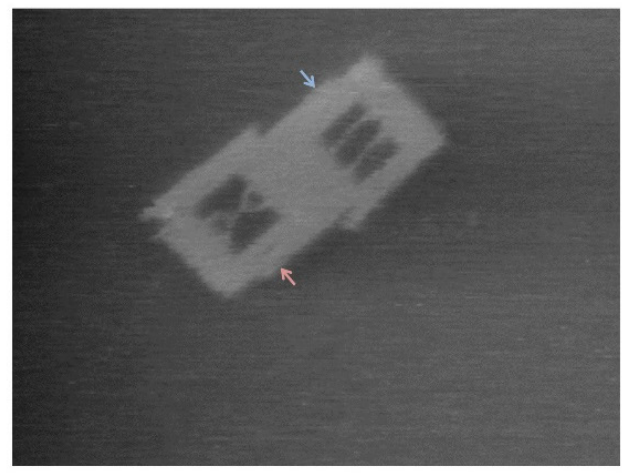

$500 \mathrm{~nm} \times 375 \mathrm{~nm}$

Figure S5. AFM images of DNA frames to prepare separated dsDNAs from topologically controlled dsDNA. AFM images of State 2 (a), State 3 (b), and State 4 (c). Blue and red arrows indicate the separated and connected (X-shaped) strands, respectively. 
(a)

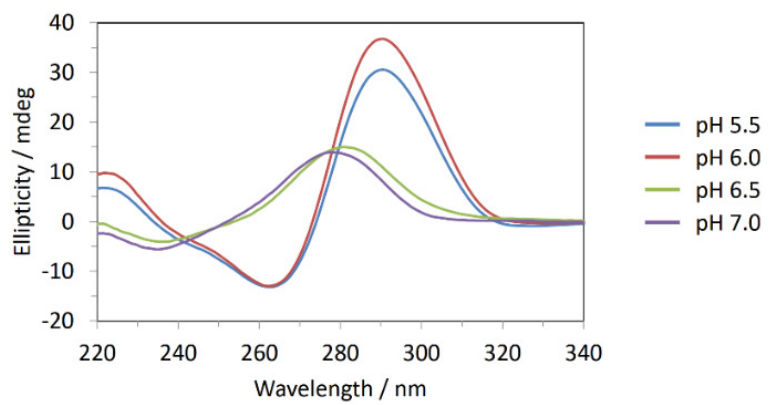

(b) $\mathrm{pH} 6.0$

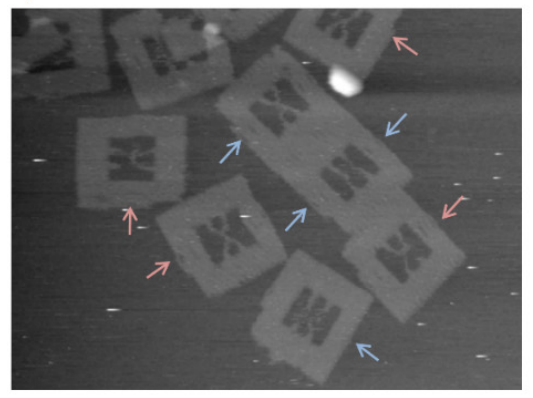

$600 \mathrm{~nm} \times 450 \mathrm{~nm}$

(c) $\mathrm{pH} 6.5$

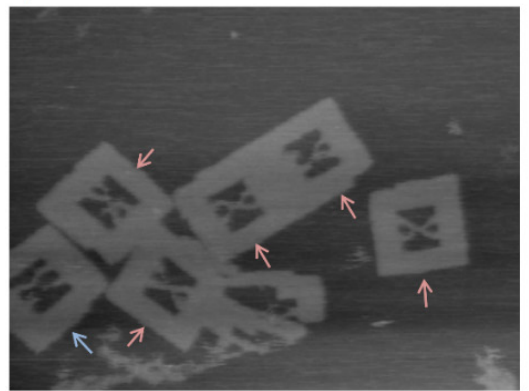

$600 \mathrm{~nm} \times 450 \mathrm{~nm}$

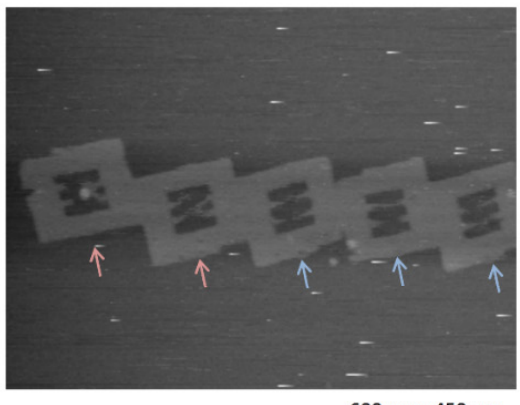

$600 \mathrm{~nm} \times 450 \mathrm{~nm}$

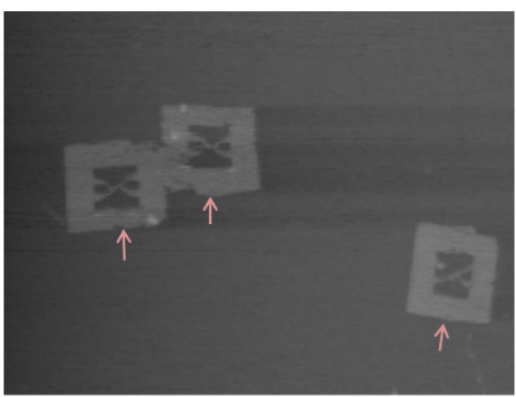

$600 \mathrm{~nm} \times 450 \mathrm{~nm}$

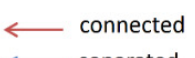

$\longleftarrow$ separated
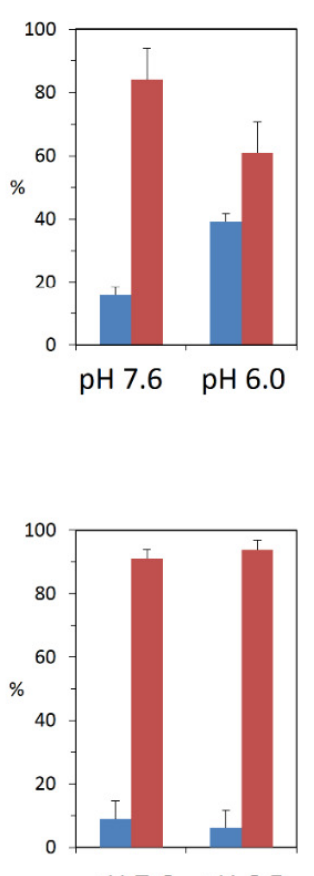

$\mathrm{pH} 7.6 \mathrm{pH} 6.5$

separated connected

Figure S6. Separation of the GQ/i-motif duplex under the pH 6.0 and 6.5 conditions. (a) CD spectra of the i-motif forming sequence at $\mathrm{pH} 5.5,6.0,6.5$, and 7.0. CD spectra were obtained in a solution containing $5 \mu \mathrm{M}$ DNA strand, $10 \mathrm{mM}$ MES buffer, $12.5 \mathrm{mM} \mathrm{MgCl}_{2}$. (b) AFM images of the DNA frame incubated at $\mathrm{pH}$ 6.0, which was prepared using the method shown in Figure 3. Summary of the proportions of $\mathrm{GQ} / \mathrm{i}$-motif duplex (connected) and separated strands at $\mathrm{pH} 7.6$ (initial state) and $\mathrm{pH}$ 6.0.

Blue and red arrows in the AFM images indicate the separated and connected (X-shaped) strands, respectively. (c) AFM images of the DNA frame incubated at pH 6.5. Summary of the proportions of GQ/i-motif duplex (connected) and separated strands at pH 7.6 (initial state) and pH 6.5. 
(a) The GQ/i-motif duplex directly assembled into the DNA frame
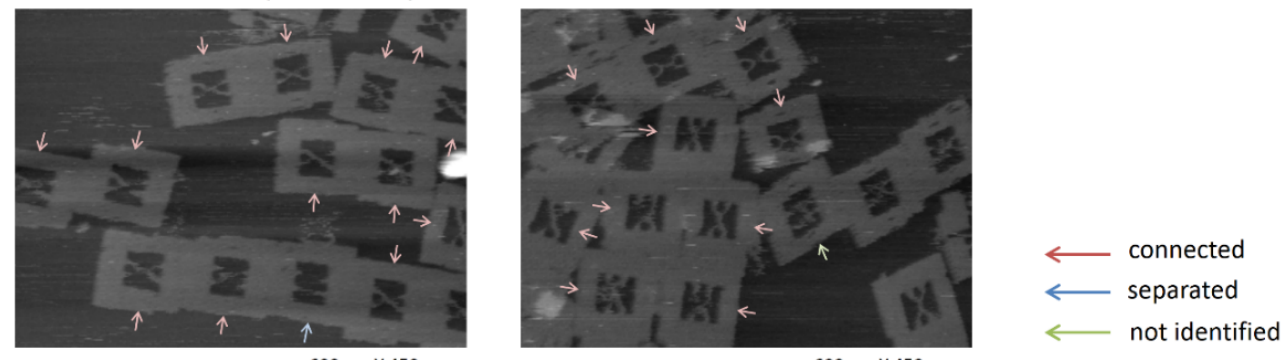

(b) The GQ/i-motif duplex above incubated with $\mathrm{K}^{+}$at $\mathrm{pH} 7.6$
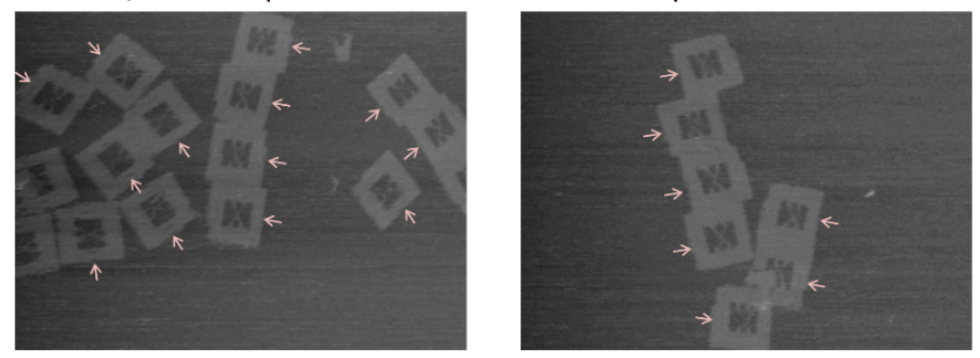

$800 \mathrm{~nm} \times 600 \mathrm{~nm}$

$800 \mathrm{~nm} \times 600 \mathrm{~nm}$

(c) The GQ/i-motif duplex above incubated at $\mathrm{pH} 5.5$
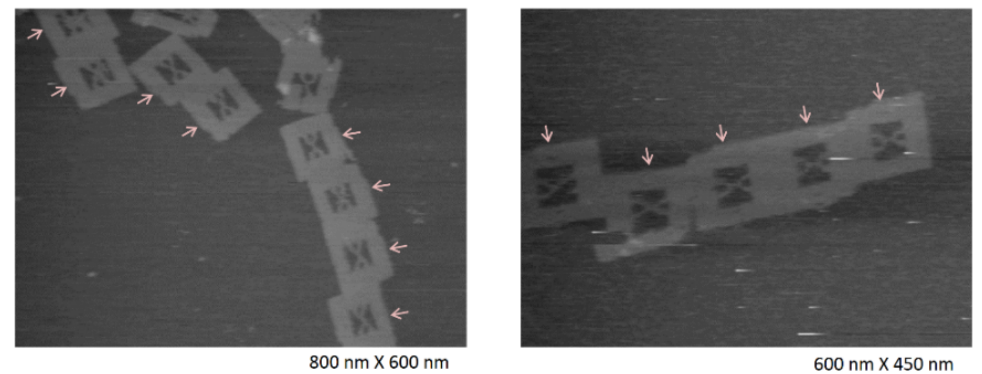

(d)

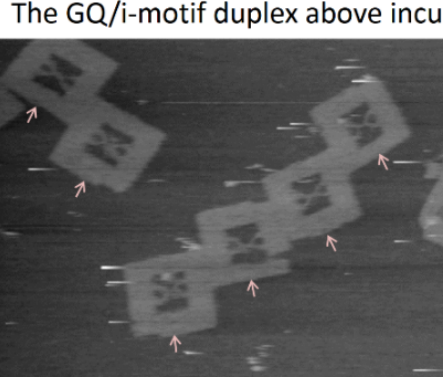

$600 \mathrm{~nm} \times 450 \mathrm{~nm}$

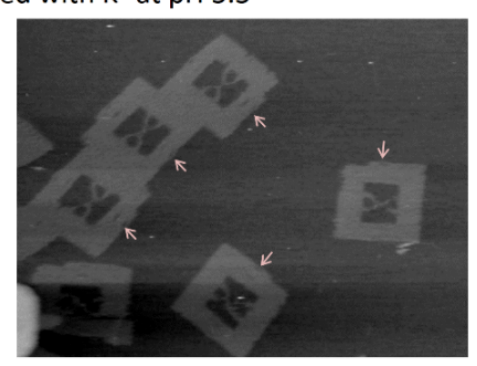

(e)

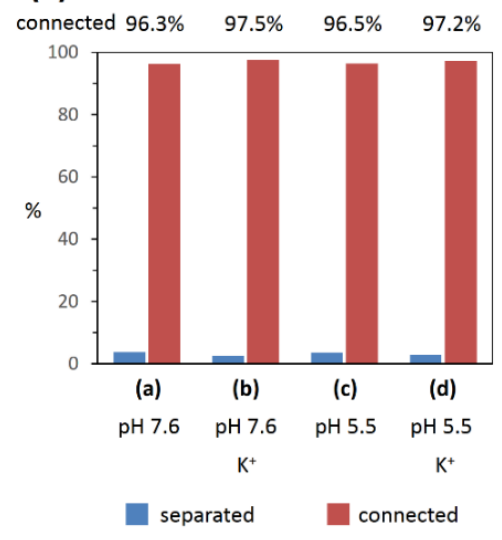

Figure S7. AFM images of the GQ/i-motif duplex assembled by annealing in the DNA frames without the sequential manipulation. To observe the separation of the GQ/i-motif duplex, the prepared GQ/imotif duplex at pH 7.6 (a) was incubated with $\mathrm{K}^{+}$at $\mathrm{pH} 7.6$ (b); at $\mathrm{pH}$ 5.5(c); with $\mathrm{K}^{+}$at $\mathrm{pH} 5.5$ (d); and their AFM images. Blue and red arrows indicate the separated and connected (X-shaped) strands, respectively. (e) Summary of the proportions of GQ/i-motif duplex (connected) and separated strands using four conditions. 
Movie S1. High-speed AFM movie of the hybridization of the GQ-/i-motif-forming ssDNA by removal of $\mathrm{K}^{+}$. Lapsed AFM images are shown in Figure 3d. Scan rate: 0.2 frames/sec. The movie is played five times faster. Image size: 150 x $150 \mathrm{~nm}$.

Movie S2. High-speed AFM movie of the dissociation of the $\mathrm{GQ} / \mathrm{i}$-motif duplex by incubation with $\mathrm{K}^{+}$ at pH 7.6. Lapsed AFM images are shown in Figure 4d. Scan rate: 0.2 frames/sec. The movie is played five times faster. Image size: 150 x $150 \mathrm{~nm}$.

Movie S3. High-speed AFM movie of the dissociation of the $\mathrm{GQ} / \mathrm{i}$-motif duplex by incubation at $\mathrm{pH}$ 5.5. Lapsed AFM images are shown in Figure 4e. Scan rate: 0.2 frames/sec. The movie is played five times faster. Image size: 150 x $150 \mathrm{~nm}$.

Movie S4. High-speed AFM movie of the dissociation of the $\mathrm{GQ} / \mathrm{i}$-motif duplex by incubation with $\mathrm{K}^{+}$ at pH 5.5. Lapsed AFM images are shown in Figure 4f. Scan rate: 0.2 frames/sec. The movie is played five times faster. Image size: 150 x $150 \mathrm{~nm}$. 